\title{
VI
}

\section{UROLOGICAL CONDITIONS IN RELATION TO VENEREAL DISEASE}

\author{
By J. SWIFT JOLY, F.R.C.S.
}

\section{Discussion}

Colonel HARRISON said that he agreed with Mr. Joly's remarks on the futility of Thompson's two-glass test in the diagnosis of posterior urethritis.

He was glad to hear Mr. Joly's remarks on the endresults of methods of treatment mostly practised by V.D. clinics and privately to-day. He wondered in what percentage of cases to-day the awful happenings which Mr. Swift Joly had related would take place. One saw a large number of cases of secondary infection, but they usually cleared up. He hoped that workers in this branch of medicine would not find they had been living in a fool's paradise and meet with a number of bad sequelæ.

He was also interested to hear of the ease with which Mr. Swift Joly could establish communication between the testicle and the vas by anastomosis. Mostly specialists had discouraged one from going on with such cases.

Mr. KING said he would like to ask the opinion of $\mathrm{Mr}$. Joly on one or two points. He had seen a number of patients in whom, in spite of prolonged treatment of the lower genital tract, pus had persisted in the urine. These were referred to a genito-urinary clinic for investigation, and occasionally such a patient was found to have a renal calculus, pyonephrosis, etc. But one type of case had been more frequent than others, namely, that in which the patient was cystoscoped, a ureteric catheter passed and a specimen of urine taken, and the latter was found to be chronically infected, the infection having come from one of the kidneys. Presumably there was a chronic pyelitis. Such a case was sent back with the diagnosis "Pyelitis due to $S$. albus," or possibly some other organism, and with the opinion that the infection was secondary to infection of the lower genital tract. 


\section{UROLOGICAL CONDITIONS}

It was further reported that nothing could be done in treatment until the lower infection had been cleared up. But his experience had been that it was impossible to clear up the lower infection while the upper trouble persisted. He would like Mr. Joly's opinion on that.

Another point concerned the importance of examining the last $\frac{1}{2}$ ounce of residual urine. Mr. Joly had said that if this was infected it was very strong evidence that the source of infection was higher in the urinary tract. It had always seemed to the speaker that when there was considerable infection of the posterior urethra, or of the glands communicating with it, that infected material seemed to pass back into the bladder frequently. $\mathrm{He}$ thought reliance on the test of the last portion of residual urine had sometimes led to error.

Mr. Claude Mills said that the dubiousness expressed by Mr. King, as to the inferences to be drawn from the last $\frac{1}{2}$ ounce of urine voided, was also felt by him. $\mathrm{He}$ thought, moreover, that little indication was likely to be derived from an analysis of this as a means of differentiating upper from lower urinary tract infections. Surely it would be contaminated by an infection of the posterior urethra, prostate or vesicles, as it would also be by an upper tract infection.

Mr. SwIFT Joly explained that he was referring to chronic cases, not those in which pus was coming from the prostate or seminal vesicles. There might be any amount of infection below the internal meatus.

Mr. Mills, resuming, said that in one case which $\mathrm{Mr}$. Joly mentioned, in which gonococci were detected very many years after the initial attack, he did not appear to have ruled out the possibility of a subsequent, and more recent, infection. One became sceptical about accepting a patient's word as absolute proof in such matters.

What Mr. Joly had said with regard to the taking of all possible measures with the object of cutting down the incidence of sterility occurring from occlusion of the vas was very interesting. The speaker made it a practice, when possible, in every severe case of acute gonococcal epididymitis to expose the epididymis through an inguinal incision, and with a blunt dissector open up the peritubular pus pockets, taking care not to tear through tubules. After relieving tension and ensuring drainage 


\section{BRITISH JOURNAL OF VENEREAL DISEASES}

in this manner, one invariably found that the pain ceased, resolution was quicker, and permanent nodules of fibrosis did not remain in the epididymis. In one case so treated, in which both sides were involved in a severe attack of acute gonococcal epididymitis, he had subsequently examined specimens of semen, and found active spermatozoa present. With regard to vas anastomosis, he used Hagner's technique, but always punctured the testis first with the object of testing for spermatogenesis. $\mathrm{He}$ had had several of these cases in which he had performed testicular puncture, and would mention that he had never obtained active spermatozoa from a testis in which sensation to pressure was absent. He would welcome the experience of others upon this. The technique employed was similar to that of gland puncture for the detection of $S$. pallida.

With regard to the opener's observation that secondary organisms were a potent factor in certain types of stricture formation, members must have met with many cases in which the original attack of gonorrhœa had been very mild-lasting perhaps only three or four weeksand free from complications, and yet later followed by a severe stricture. He had seen many patients who had had several attacks of gonorrhœa, some with a chronic gleet rich in secondary organisms, and yet free from stricture. As to the secondary organisms found in the gleet, which practically always accompanies the oldstanding stricture, he had always held that the organisms resulted from the stricture rather than that the stricture resulted from the organisms. The chronically inflamed patch of mucous membrane on the proximal side of a stricture afforded a very favourable nidus for the growth of these secondary organisms; a man with a stricture, having connection with a normal woman, would readily acquire such.

Mr. Hamish Nicol said he very much appreciated the opening address. He saw many cases of gonorrhœa but very few strictures.

For many years he had treated large numbers of cases of gonorrhœa, but none had developed stricture. It is quite common to find signs of early stricture, such as Mr. Swift Joly had spoken of, which, after dilatation, gave no further trouble.

The only strictures he had under treatment were in 


\section{UROLOGICAL CONDITIOÑS}

elderly men. At the Manor House Hospital he had many such cases, tight relapsing strictures which required constant treatment by dilatation.

He would like to ask Mr. Swift Joly if he is of opinion that stricture is rare under the modern treatment of gonorrhœa?

He had long given up the two-glass test as a method of diagnosis. He agreed with Mr. Swift Joly that the anterior urethra should be first washed out if one wished to find out the condition of the posterior urethra by examination of the urine.

Mr. T. J. WRIGHT remarked that a year ago a paper was read by Mr. Jocelyn Swan, who warned his hearers against the use of a long Kollmann's dilator in the treatment of strictures, stating that there were cases so dilated that permanent incontinence of urine had followed. $\mathrm{He}$, the speaker, had since then relied on bougies, as he had feared incontinence occurring. He would like to know whether Mr. Swift Joly agreed with Mr. Jocelyn Swan's remarks on that matter.

Dr. T. Anwyl Davies also thanked Mr. Swift Joly for his address.

He said the text-books stated that in 50 per cent. of cases of bilateral epididymitis sterility resulted, but he thought the actual proportion of sterility was much lower than that; he had seen many cases with bilateral nodules in the epididymis in which children had been added to the family afterwards. He would like to hear Mr. Swift Joly's opinion on that.

He was interested in what Mr. Joly said about the differential diagnosis between disease of the upper and lower urinary tract by examination of the last $\frac{1}{2}$ ounce of residual urine. One was accustomed to take note of this, but he would like to hear how Mr. Joly would differentiate between a case with a perinephritic abscess, or a hydronephrosis and a coincident prostatitis or vesiculitis. One had treated prostatitis and vesiculitis for several months, wondering whether a higher infection was present, although no evidence seemed to exist of an upper urinary tract infection, yet one was conscious this did occur. The figures at the Whitechapel Clinic agreed with those of Mr. Swift Joly, that three or four days after infection with gonorrhoa 90 per cent. to Ioo per cent. developed a posterior urethritis. His experience at 


\section{BRITISH JOURNAL OF VENEREAL DISEASES}

the clinic was that prostatitis was not the commonest sequel ; the commonest was a vesiculitis.

With reference to the secondary organisms causing the sequelæ following gonorrhœa, from experience in culturing these cases as a routine, he thought the number of cases supposed to be due to secondary organisms could be much reduced in favour of the gonococcus.

$\mathrm{He}$ agreed with the remark of Mr. Hamish Nicol that ten to fifteen years ago venereal clinics were full of cases of stricture, whereas nowadays such cases were seldom seen in the average clinic.

Major F. C. Doble said the general feeling seemed to be one of pessimism about mixed or secondary infections, but some of the organisms found were comparatively harmless, especially the diphtheroids. He had seen many cases of diphtheroid infection, but had not found serious sequelæ associated with them. A mixed infection might be a blessing in disguise, for sometimes it killed out the gonococcus and enabled the tissues to react better afterwards.

Dr. ORPWOOD PRICE, referring to secondary organisms, said that until some means were found of differentially culturing organisms it was of little use to talk of what organisms were and what were not found. Until either a different technique or a different medium was found he felt it was almost impossible to say whether the gonococcus was still persistent, or whether the symptoms present were due to secondary organisms, such as staphylococci, streptococci, diphtheroids, pneumococci, or others.

Dr. Osmond said his colleague did a number of rectal cultures, particularly in women, and found no difficulty in culturing the gonococcus; in spite of the fact that $B$. coli were all over the place. But they had not been found in the cervical or urethral specimens.

Mrs. Hemmant remarked that, since the urethra was one of the commonest sites of infection in women, she would like to hear why, in women, one so rarely found an ascending infection?

Mr. Claude Mills said that Dr. Osmond's pronouncement as to the frequency with which he was able to culture gonococci from the rectum of the female patient with gonorrhœea was of very great clinical importance. The speaker had always been unable to explain why the 


\section{UROLOGICAL CONDITIONS}

rectum did not become infected with gonococci in every female suffering from gonorrhœe. It must necessarily follow that the anus is being pus-poulticed during each menstrual period in such cases, and yet, thank goodness, symptomatic gonococcal proctitis, as recognised clinically, is a comparatively rare occurrence. Dr. Osmond's findings surely suggest the possibility of re-infections of, say, the urethra, by means of pus conveyed from the anus beneath the dressings worn at successive menstrual periods. He was afraid, however, that the interest of Dr. Osmond's statement had caused him to stray somewhat from the subject under discussion.

Dr. ANWYL DAvies said that probably gonococci were present in the rectum in 90 per cent. of cases, but how often did their presence cause trouble or inconvenience ? His experience was that if left alone they quickly disappeared in most cases.

Colonel HARRISON said Dr. Osmond's remark was to show that if the gonococcus was there it could be cultivated, and he had instanced the case of specimens from the rectum only for this purpose. The meeting was not discussing proctitis in females.

The PRESIDENT said she had been very interested in the opening address, and she felt very grateful indeed for it.

At the Royal Free Hospital she attempted to teach the women students something about gonorrhœa and syphilis, and she concentrated her teaching on gonorrhœa on the disease as seen in women, and a frequent remark was, "Tell us about gonorrhœa in men." It had been very interesting to hear about these chronic infections in men, with or without stricture, with or without kidney damage. Mr. Swift Joly said-she did not know whether this was one of his pessimistic evenings - that these chronic infections could never be cured, and her own reflection was: What about the wife of the man who had a chronic infection of the genito-urinary tract ? Some of the chronic discharge cases which she saw in married women, in which films and cultures showed no gonococci, were wives of chronically infected men. If patients were questioned about their husbands, the majority professed blank ignorance, while some replied with a show of indignation, "There's nothing the matter with Daddy." And when "Daddy" came back from the clinic the 


\section{BRITISH JOURNAL OF VENEREAL DISEASES}

wives reported that their menfolk were well, the truth being either that he had not gone to the clinic or the wife came with an embellished tale.

She was interested in Mr. King's reference to chronic pyelitis in men because she would say that in women that was the commonest kidney or bladder infection, i.e., a chronic or sub-acute pyelitis, sometimes showing symptoms, sometimes not. They were very tiresome cases to treat. The urologist at her hospital tended to say, "You must get rid of the lower infection before you ask us to deal with the pyelitis," and so those concerned proceeded in a circle from time to time.

Mr. SwIFT Joly in his reply said he wished, in the first place, to thank those present for the exceedingly kind way in which they had received his communication.

Several speakers had mentioned the question of the proportion of cases in which a persisting infection followed gonorrhœa. He had no accurate figures from public clinics, but it was undoubtedly very low. Cases of stricture filled the urological clinics because they attended week after week for practically the remainder of their lives. The number of attendances for this condition was enormous, but the actual number of patients was comparatively small. He thought it incontestable that the venereal clinics were doing very good work in reducing the number of stricture cases, and he based this opinion on the fact that the number of operations for stricture at St. Peter's Hospital was steadily falling. Before the war about Ioo internal urethrotomies were performed every year, now the number was about thirty, and it was still falling.

Several speakers referred to pyuria. Certainly, in the female, pyelitis was the most common cause of pus in the urine. Apart from stricture cases, he thought that the same was true of the male. It was extraordinarily difficult to cure a chronic coccal pyelitis. Drugs given by the mouth had little or no effect. Salvarsan had been recommended, but he had never obtained a cure by means of this drug, though in many cases the patient's condition had been materially improved. The same applied to intravenous injections of urotropin. The ketogenic diet had proved to be uncertain in this type of case, though it had undoubted value in B.C.C. infections.

With regard to chronic pyelonephritis, he thought the 


\section{UROLOGICAL CONDITIONS}

outlook was hopeless. The condition persisted in spite of treatment, and usually ended up as a pyonephrosis. The gradual deterioration of the kidney could easily be watched by means of intravenous pyelography. $\mathrm{He}$ therefore advised nephrectomy much earlier than formerly, as he considered it to be the only means of curing the infection. Of course, this operation was only applicable to cases of unilateral infection.

In cases of infected calculus and similar conditions he was becoming much more radical, and now advised nephrectomy where formerly he was content to remove the stone, and he was convinced that the results were much better. His reason for this change was that the infection tended to spread from one side to the other, and that if a conservative operation was performed in a case of unilateral infection, the patient frequently returned months or years afterwards with both kidneys infected.

He was asked what he thought of the value of Kollmann's dilators in the treatment of stricture. Frankly, he preferred solid bougies. If the stricture was tough and difficult to dilate, the bars of the Kollmann dilator bent, and the actual calibre of the stricture was less than that indicated on the dial of the instrument. He considered Kollmann's instrument to be invaluable in the treatment of chronic urethritis, but there was not much scope for it in the treatment of really difficult strictures. 